\title{
Method of power consumption calculation of air conditioning systems on the basis of probability- statistic climate model
}

\author{
Olga Malikova ${ }^{1, *}$ \\ ${ }^{1}$ Moscow State University of Civil Engineering, 26, Yaroslavskoe shosse, 129337, Moscow, Russia
}

\begin{abstract}
The article discusses the methodology for calculating the annual, seasonal and monthly consumption of heat, cold, electricity and water for air conditioning systems based on the temperatures and enthalpies of outdoor air averaged for each weather zone during the working day according to a probabilistic-statistical climate model. The article contains a brief description of the engineering methodology for quick manual calculation of resource consumption with a comparison of the results when using simplified tables of climatic information about weather zones of various external air purification in devices of the central air conditioning system. An example of calculating the annual costs for a system controlled by the "optimal modes" method according to the direct flow scheme with a bypass of the humidification chamber and the controlled process in the air cooler is studied. The advantages of the proposed engineering method lie not only in accuracy, but also in that it allows you to consider the operation of the installation during the year with greater detail for each air purifier. It is shown that the simplified procedure is suitable for use, since it gives discrepancies with machine calculation, which is no more than $10 \%$, which is acceptable for engineering practice.
\end{abstract}

\section{Introduction}

A significant drawback of the procedure for calculating energy consumption in the Russian regulatory document SP 50.13330. 2012 "Thermal protection of buildings" is the lack of estimates of energy costs for cooling the premises in the warm season. According to most experts in the field of energy saving, accounting for energy consumption to maintain the indoor climate is most indicative if it is calculated for the whole year [1-5]. The greatest difficulty in calculating energy consumption is accounting for processes associated with humidification or dehumidification of air, since the intensity of each of these processes at certain intervals should be reflected. The main objective of the developed methodology is to provide designing with the ability to calculate the annual consumption of heat, electricity and water by air conditioning systems (AC). Nowadays, in the section of project documentation "Measures to ensure compliance with the requirements of energy efficiency and the requirements for equipping buildings, constructions and structures with meters for used energy resources", the costs of energy resources are taken into account only for heating and

${ }^{*}$ Corresponding author: KryuchkovaOU@mgsu.ru 
ventilation. Studies have shown that energy costs for air conditioning are not taken into account due to the lack of a single approved calculation procedure [6]. The article discusses the methodology for calculating the annual, seasonal and monthly consumptions of heat, cold, electricity and water for AC systems based on the temperatures and enthalpies of outdoor air averaged for each weather zone during working hours according to the probability-statistical climate model $[7,8,9]$.

\section{Method of calculation}

The main input data for the calculation are: climate data in the form of a probabilisticstatistical model; requirements for internal conditions in the premises of the building (temperature, relative humidity); heat-moisture ratio of the indoor air treatment process for warm and cold periods of the year; operation mode of the air conditioning system; estimated air flow in the $\mathrm{AC}$ unit; minimum required external air consumption; electric power of electric motors of fans and pumps of air heaters and humidifiers, refrigeration station; enthalpy of dew point for summer and cold periods of the year (when regulated by the dew point method). The methodology deals only with the treatment of external and recirculated air for supply to the room as a supply air $[10,11,12]$. All heat losses, heat and moisture, which make up the heat and refrigeration load on the AC system, are considered known.

As the designed internal conditions, the optimum or permissible temperature and relative humidity for the cold (CP) and warm (WP) periods of the year are taken differentially. In the transition mode, the internal air temperature $t_{\mathrm{i}},{ }^{\circ} \mathrm{C}$, is determined as the arithmetic mean between the calculated temperature in the served area of the room in summer and winter modes.

Depending on the adopted air treatment scheme in the AC unit, the area of possible combinations of temperature and relative humidity in the construction area should be divided into weather zones in the $I-d$ diagram [13]. This area can be approximately limited by lines of constant relative humidity $\varphi=100 \%$ and $\varphi=15 \%$, as well as by a line of constant heat content equal to the calculated enthalpy of the outside air in the warm season.

The implementation of the methodology begins with the application on the $I-d$ diagram of an oblique-angled quadrangle of the region of optimal or admissible parameters of internal air formed by isotherms of normalized temperature values and lines of normalized values of maximum and minimum relative humidity. Through the points that limit the quadrangle to the maximum normalized temperature values in the warm season, it is necessary to draw lines with the angular coefficient of the process ray in the warm season, and through the points bordering the bottom of the quadrangle with the minimum normalized temperature in the cold season, draw lines with the angular coefficient of the process ray of changing the state of air in the cold season, and mark on these lines the corresponding working temperature differences.

In each weather zone, a point of outdoor air is plotted according to the average parameters of the outdoor air for the zone: enthalpies $I_{m} i, k J / k g$ and moisture content $d_{m} i, g / k g$, determined according to the tables made on the basis of preliminary computer calculations $[13,14]$. With the parameters of the outdoor air characterized by this point, the instantaneous flow rates of heat, cold, water and electricity are determined by the formulas $[14,15,16,17]$. According to the table corresponding to the selected air treatment scheme, the operating time $\mathrm{z}_{\mathrm{i}}, \mathrm{h}$, of each unit is determined by zone. The annual consumption of heat, cold, water and electric energy are defined as the product of the instantaneous consumptions of energy indicators and the operating time of the corresponding unit for the whole year (or a month, season on demand).

The article presents an example of calculating the annual, seasonal, monthly consumption of heat, cold, electricity and water for the AC system regulated by the "optimal modes" 
method according to the direct-flow circuit with a bypass of the humidification chamber (bypass) and a controlled process in the air cooler. The calculation is carried out in tabular form. The calculation is performed for the premises of the exhibition hall in the city of Moscow, operating from 9-00 to 18-00 at a five-day working week with two days off. The parameters of the external environment which are average for the working time are chosen for this time interval.

Optimal indoor air parameters: for WP of the year $t_{\mathrm{i}}=25{ }^{\circ} \mathrm{C}, \varphi=60 \%$ and the angular coefficient of the heat-moisture ratio $\varepsilon^{\mathrm{w}}=11350 \mathrm{~kJ} / \mathrm{kg}$, for $\mathrm{CP}$ of the year $t_{\mathrm{i}}=18{ }^{\circ} \mathrm{C}, \varphi=30 \%$ and the angular coefficient of the heat-moisture ratio $\varepsilon^{\mathrm{c}}=16000 \mathrm{~kJ} / \mathrm{kg}$. Operative temperature difference $\Delta \mathrm{t}=4^{\circ} \mathrm{C}$. Supply air flow rate $L=5480 \mathrm{~m}^{3} / \mathrm{h}$. We consider all heat transfers during the year known for each month. The project adopted a chiller with air-cooled condenser, with an integrated hydraulic module with a nominal cooling capacity of $17.23 \mathrm{~kW}$ and a generating capacity of compressors of $6.11 \mathrm{~kW}$.

We build the area of supply air parameters $\mathrm{F}_{1} \mathrm{~F}_{2} \mathrm{~F}_{3} \mathrm{~F}_{4}$ (Fig. 1). Then, we divide the total area of possible combinations of temperature and relative humidity in Moscow into weather zones corresponding to the direct-flow AC system, which serves a room, with the bypass of the humidification chamber (bypass) and the process being controlled in the air cooler. The boundaries of the weather zones for the adopted air treatment scheme in accordance with Fig. 1 are given in Table 1.

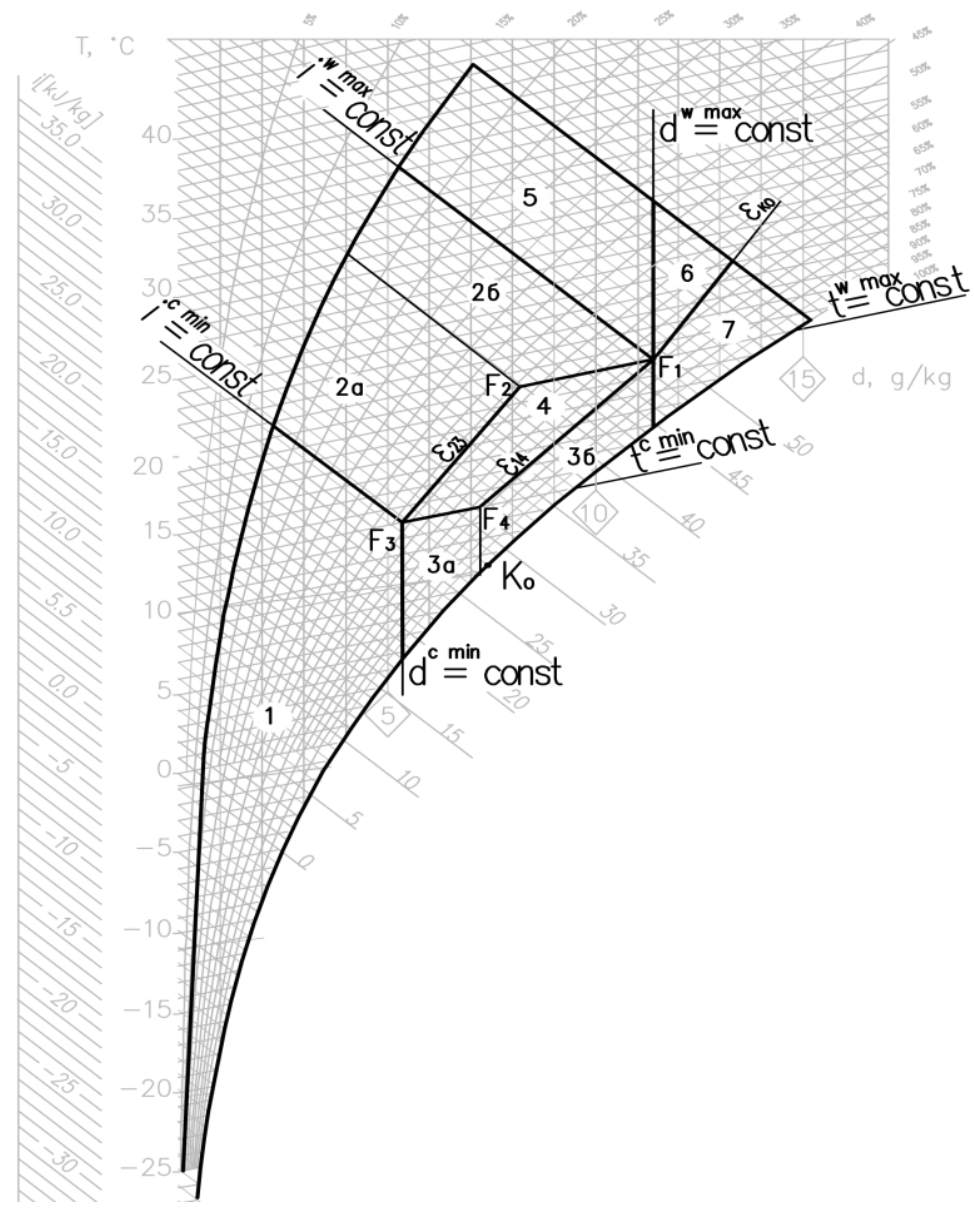

Fig. 1. Zones of supply air treatment at direct flow circuit with bypass through the humidification chamber. 
Where: 1 - ZONE 1: heating of external air in the air-heater of I-heating, humidification of part of air in the adiabatic combustion chamber and mixing of heated dry air along the bypass line and air passing through the humidification chamber; 2 - ZONE 2: heating the air in the I-heating air heater, moistening part of the air in the adiabatic humidification chamber and mixing the heated dry air through the bypass line and the air passed through the humidification chamber; 3 - ZONE 3: air heating in who-heater I-heating; 4 - ZONE 4: supply of untreated outdoor air to the rooms; 5 - ZONE 5: cooling process in the air cooler; 6 - ZONE 6: heating in I-heating air heater and cooling in air cooler.

Table 1. Description of the boundaries of weather zones.

\begin{tabular}{|c|c|c|c|}
\hline Zone & $\begin{array}{l}\text { Next } \\
\text { zone }\end{array}$ & Zone border & Definition of border \\
\hline 1 & $\begin{array}{l}\text { Zone } 3 \\
\text { Zone } 2\end{array}$ & $\begin{array}{l}\text { Minimum supply air moisture content in CP } \\
\text { Minimum heat content of the supply air in } \mathrm{CP}\end{array}$ & $\begin{array}{l}\mathrm{d}^{\mathrm{c} \min }=4.8 \mathrm{~g} / \mathrm{kg} \\
\mathrm{I}^{\mathrm{c} \min }=23.2 \mathrm{~kJ} / \mathrm{kg}\end{array}$ \\
\hline 2 & $\begin{array}{l}\text { Zone } 4 \\
\text { Zone } 5 \\
\text { Zone } 4\end{array}$ & $\begin{array}{l}\text { The F2F3 line connecting the points to the maximum } \\
\text { relative humidity of the WP and CP } \\
\text { Maximum heat content of supply air in WP. } \\
\text { Maximum supply air temperature in WP. }\end{array}$ & $\begin{array}{c}\varepsilon_{23}=7400 \mathrm{~kJ} / \mathrm{kg} \\
\mathrm{I}^{\mathrm{w} \max }=50.05 \mathrm{~kJ} / \mathrm{kg} \\
\mathrm{t}^{\mathrm{w} \max }=21^{\circ} \mathrm{C}\end{array}$ \\
\hline 3 & $\begin{array}{l}\text { Zone } 4 \\
\text { Zone } 4 \\
\text { Zone } 6\end{array}$ & $\begin{array}{l}\text { The F1F4 line connecting the points to the minimal } \\
\text { relative humidity at-precision air in WP and CP. } \\
\text { Minimum supply air temperature in CP. } \\
\text { Maximum supply air moisture content in WP. }\end{array}$ & $\begin{array}{c}\varepsilon_{14}=3800 \mathrm{~kJ} / \mathrm{kg} \\
\mathrm{t}^{\mathrm{cmin}}=14{ }^{\circ} \mathrm{C} \\
\mathrm{d}^{\mathrm{wmax}}=11.4 \mathrm{~g} / \mathrm{kg}\end{array}$ \\
\hline 4 & $\begin{array}{l}\text { Zone } 2 \\
\text { Zone } 2 \\
\text { Zone } 3 \\
\text { Zone } 3\end{array}$ & $\begin{array}{l}\text { The F2F3 line connecting the points to the maxi } \\
\text { relative humidity at-precision air in WP and CP. } \\
\text { Maximum supply air temperature in WP. } \\
\text { The F1F4 line connecting the points to the minimal } \\
\text { relative humidity at-precision air in WP and CP. } \\
\text { Minimum supply air temperature in CP. }\end{array}$ & $\begin{array}{c}\varepsilon_{23}=7400 \mathrm{~kJ} / \mathrm{kg} \\
\mathrm{t}^{\mathrm{w} \max }=21^{\circ} \mathrm{C} \\
\varepsilon_{14}=3800 \mathrm{~kJ} / \mathrm{kg} \\
\mathrm{t}^{\mathrm{c} \min }=14^{\circ} \mathrm{C}\end{array}$ \\
\hline 5 & Zone 2 & $\begin{array}{l}\begin{array}{l}\text { Angular coefficient of line characterizing air cooler } \\
\text { operation. }\end{array} \\
\text { Maximum heat content of supply air in WP. }\end{array}$ & $\begin{array}{c}\varepsilon_{\mathrm{Ko}}=6180 \mathrm{~kJ} / \mathrm{kg} \\
\mathrm{I}^{\mathrm{w} \max }=50.05 \mathrm{~kJ} / \mathrm{kg}\end{array}$ \\
\hline 6 & Zone 5 & $\begin{array}{l}\text { Angular coefficient of line characterizing air cooler } \\
\text { operation. } \\
\text { Maximum supply air moisture content in WP. }\end{array}$ & $\varepsilon_{\mathrm{\kappa o}}=6180 \mathrm{~kJ} / \mathrm{kg}$ \\
\hline
\end{tabular}

\section{Calculation results}

It should be borne in mind that the obtained results of energy consumption by AC systems in Table 2 can be considered as quite probable on the basis of the last 30 years of meteorological measurement of climatic indicators. In each particular year they can be less or more. Setting the average heat-humidity ratio of indoor air for a warm or cold time period reduces the accuracy of the calculation. In a monthly calculation, it is possible to correct the heatmoisture ratio for each month when establishing boundaries between weather zones. 
Table 2. Comparison of calculation results according to simplified method by manual account and method using computer.

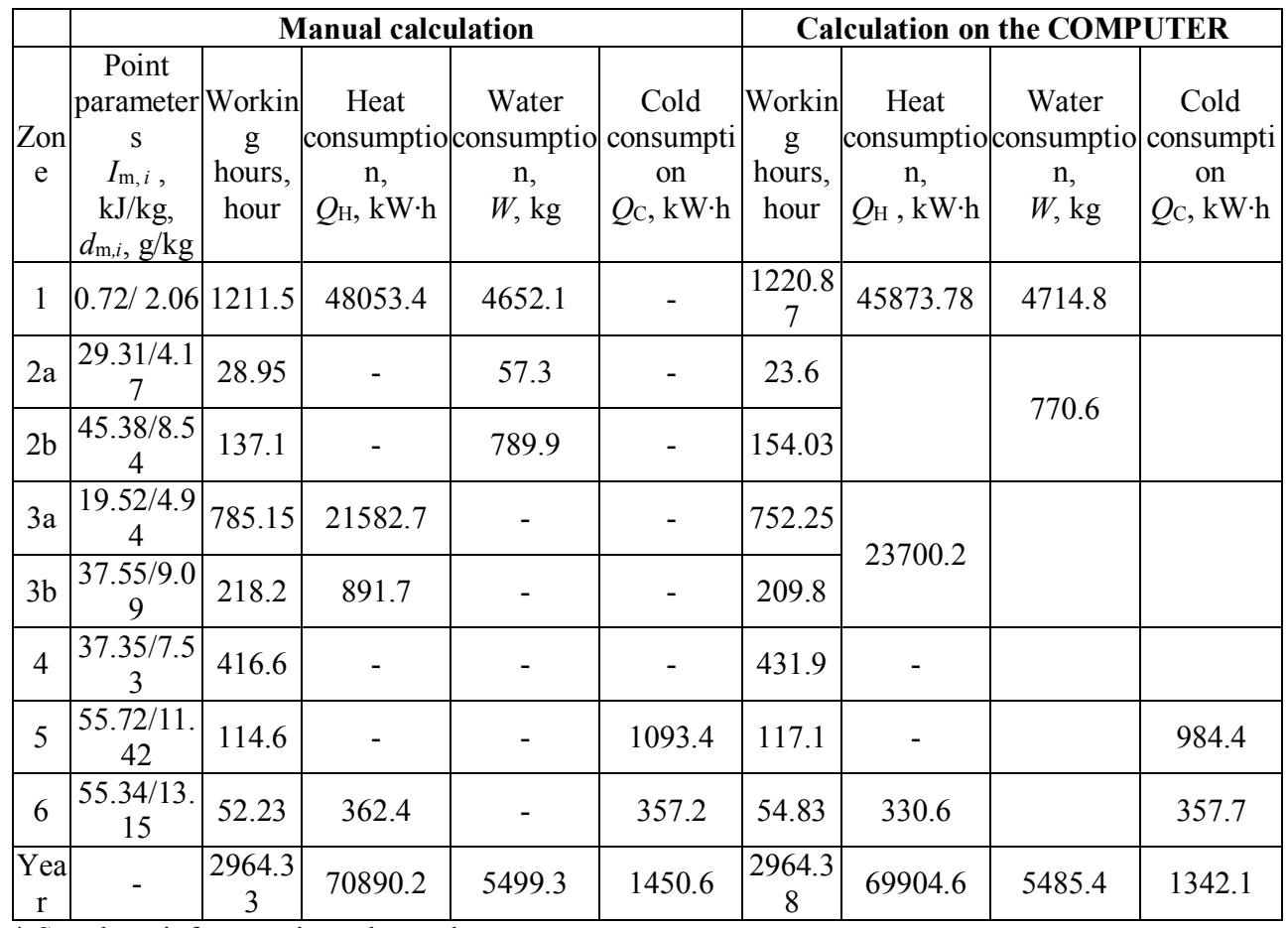

* Supply unit fan runs in each weather zone

Table 3. Accuracy of calculations, $\%$, of the annual consumption between methods according to simplified procedure or using computer.

\begin{tabular}{|c|c|c|c|c|}
\hline \multirow{2}{*}{ Zone } & \multicolumn{4}{|c|}{ Accuracy of calculations, \%, of the annual consumption between methods } \\
\cline { 2 - 5 } & $\begin{array}{c}\text { of heat by the air } \\
\text { heater }\end{array}$ & of water & of cold & of working hours \\
\hline 1 & 4.54 & -1.35 & - & -0.77 \\
\hline $2 \mathrm{a}+2 \mathrm{~b}$ & - & 9.94 & - & -6.52 \\
\hline $3 \mathrm{a}+3 \mathrm{~b}$ & -5.17 & - & - & 4.19 \\
\hline 4 & - & - & - & -3.67 \\
\hline 5 & - & - & 9.97 & -2.18 \\
\hline 6 & 8.77 & - & -0.14 & -4.98 \\
\hline Year & 1.39 & 0.25 & 7.48 & -0.77 \\
\hline
\end{tabular}

The data in Table 3 convince us that the simplified method is suitable for use, since it gives discrepancies with computer calculation that do not exceed $10 \%$, which is acceptable for engineering practice.

\section{Discussion}

The advantages of the proposed methodology for calculating energy indicators are explained by its underlying wider climate base than the SP 131.13330.2018 "Construction Climatology" can provide. Unfortunately, this also involves difficulties in introducing the 
proposed methodology, for the implementation of which it is necessary to process the primary climatological information over a long period of time.

The advantages of the proposed engineering methodology are not only accuracy, but also the fact that it allows us to consider the operation of the central air conditioning system during the year with more detail, to determine the energy consumption of each of the air processing devices included in the air conditioning unit and the time of its operation.

\section{Conclusion}

The main results of calculations according to the methodology are: annual or monthly heat consumption by AC systems serving the room (for monthly calculation); the duration of heat and cold consumption and power consumption (in months for monthly calculation, in hours of system operation), which differ from the calculation simulated on a computer by an amount not exceeding the allowable for engineering practice.

The calculation results can be used:

a) to determine the level of energy characteristics of newly designed, reconstructed and existing buildings;

b) to compare the energy characteristics of various alternative solutions of the designed building;

c) to assess the proposed energy conservation measures in existing buildings by calculating energy consumption with and without taking energy conservation measures;

d) to forecast energy needs at the regional or national level by calculating the energy consumption of typical buildings representing the construction market.

\section{References}

1. K.J. Chua, S.K. Chou, W.M. Yang, J. Yan, Applied Energy 104, 87-104 (2013)

2. A. Afram, F. Janabi-Sharifi, Applied Thermal Engineering 67(1-2), 507-519 (2014)

3. L. Pérez-Lombard, J. Ortiz, C. Pout, Energy and Buildings 40(3), 394-398 (2008)

4. L. Kajtár, J. Gräff, M. Kassai, J. Szabó, 12th International Conference on Indoor Air Quality and Climate 2011.1 (2011)

5. M.A. Karim, M. Mahmudul Hasan, M. Imran, H. Khan, Energy and Buildings 203 (2019) https://doi.org/10.1016/j.enbuild.2019.109396

6. E.G. Malyavina, O.Y. Kryuchkova, Environmental engineering, 8-th International Conference 19-20, 776-780 (2011)

7. F. Oldewurtel, D. Sturzenegger, M. Morari, Applied Energy 101, 521-532 (2012)

8. E.G. Malyavina, O.Y. Malikova, IOP Conference Series: Materials Science and Engineering Moscow 365 (2018) doi:10.1088/1757-899X/365/2/022009

9. F. Oldewurtel, C.N. Jones, A. Parisio, M. Morari, IEEE Transactions on Control Systems Technology 22(3), 1198-1205 (2013)

10. Chaoqun Zhuang, Shengwei Wang, Rui Tang, Energy Procedia 158, 3202-3207 (2019) https://doi.org/10.1016/j.egypro.2019.01.1008

11. M. Georgios, K. Orehounig, J. Carmeliet, Energy 156, 709-724 (2018) https://doi.org/10.1016/j.energy.2018.05.081

12. R. Tang, S.W. Wang, K. Shan, H. Cheung, Energy 151, 771-781 (2018)

13. E. Malyavina, O. Malikova, IOP Conf. Ser.: Mater. Sci. Eng. 451, 012104 (2018) https://doi.org/10.1088/1757-899X/451/1/012104 
14. E. Malyavina, O. Malikova, IOP Conf. Ser.: Mater. Sci. Eng. 463, 022065 (2018) https://doi.org/10.1088/1757-899X/463/2/022065

15. M.T. Fauchoux, C.J. Simonson, D.A. Torvi, ASHRAE Transactions 112, 440 (2007)

16. Jiacheng Ni, Xuelian Bai, Renewable and Sustainable Energy Reviews 67, 625-640 (2017) https://doi.org/10.1016/j.rser.2016.09.050.

17. Xiangguo Xu, Ziwen Zhong, Shiming Deng, Xiaobo Zhang, Energy and Buildings 162, 163-176 (2018) https://doi.org/10.1016/j.enbuild.2017.12.038 